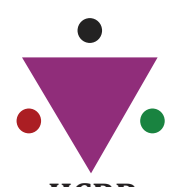

IJCRR

Section: Healthcare

Sci. Journal Impact

Factor: 6.1 (2018)

ICV: $90.90(2018)$

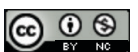

Copyright@IJCRR

\section{Evaluation of Cognizance, Attitude, and Practice of Needlestick and Sharps Injuries among Dental Health Care Professionals at Nellore, India - A Cross-Sectional Study}

\section{Dhigvijay Arepogu ${ }^{1}$, Nirmala SVSG ${ }^{2}$, Saranya Jeepalyam ${ }^{1}$, Sivakumar Nuvvula ${ }^{3}$, Akhila Kethireddy ${ }^{4}$}

'Post graduate student, Department of Pedodontics and Preventive Dentistry, Narayana Dental College and Hospital, Nellore, Andhra Pradesh, India; ${ }^{2}$ Professor, Department of Pedodontics and Preventive Dentistry, Narayana Dental College and Hospital, Nellore, Andhra Pradesh,

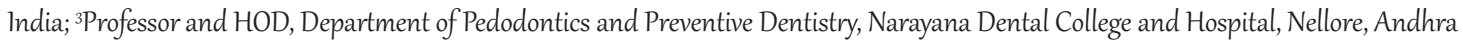
Pradesh, India; 4 Former Resident, Department of Pedodontics and Preventive Dentistry, Narayana Dental College and Hospital,

Nellore, Andhra Pradesh, India.

\title{
ABSTRACT
}

Aim: This study aimed to evaluate the cognizance, attitude, practice, prevalence of Needlestick, and sharps injuries among dental professionals at Nellore, India.

Materials and Methods: Cross-sectional study of 276 dental professionals were given a questionnaire and were informed about the purpose of the study and the study design by using a Convenience sampling technique. Third-year and final year UG students, dental house surgeons, postgraduate students, and dental practitioners were included in the survey as dental professionals. Pretested and predesigned questionnaire forms gave to dental professionals. Statistical analysis was performed by employing the statistical package, SPSS version 13. A comparison of these variables between the dental health care professionals made using Pearson's Chi-square test.

Results: $96 \%$ of dental professions considered Needle Stick Injury (NSI) Needle Stick Injury transmit diseases and $59 \%$ of dental professionals knew about the Universal Precaution Guidelines $(P<0.05)$. In case of an accidental NSI, $64.4 \%$ of the dental professionals reported that they would have first contacted a medical emergency room, $85.96 \%$ did not report because the injury was due to sterile needle. $80.70 \%$ had an occurrence of NSI during device use. $72 \%$ followed one-handed needle recapping technique or scoop technique, and $36.95 \%$ used needle burner and syringe destroyer to dispose of a needle.

Conclusion: Dental practitioners and postgraduates were with adequate knowledge regarding NSIs. Third-year, Final year undergraduate students and Dental house surgeons had poor knowledge regarding NSIs.

Key Words: Dental professionals, Needlestick, Sharp injuries, PEP (Post-exposure prophylaxis), Universal Precaution Guidelines

\section{INTRODUCTION}

An exposure can define as a percutaneous injury or contact of mucous membrane or no intact skin that occurs during person employment with blood, saliva, tissue, or other body fluids that are potentially infectious. ${ }^{1}$ A needle stick injury (NSI) defined as an accidental skin-penetrating a stab wound from a hollow-bore needle (or any sharp) containing another person's blood or body fluid. Sharps injury (SI) defined as a skin-penetrating stab wound caused by sharp instruments and accidents in a medical setting. ${ }^{2}$
Health care workers with an increased risk of accidental needle stick injuries (NSI) is due to the environment in which they work. Blood-borne diseases such as HIV, hepatitis B, hepatitis $\mathrm{C}$, and other diseases result in the risk of occupational acquisition to workers. 2.6\% for HCV, (Hepatitis C virus) $5.9 \%$ for $\mathrm{HBV}$ (Hepatitis B virus) and $0.5 \%$ for $\mathrm{HIV}$, (Human Immunodeficiency Virus. 16,000 HCV infections and $66,000 \mathrm{HBV}$ infections seen according to a WHO study with the annual estimated proportions of Healthcare workers (HCW) exposed to blood-borne pathogens in HCW worldwide. ${ }^{3}$

\section{Corresponding Author:}

Dr. Nirmala SVSG, MDS, Professor, Department of Pedodontics and Preventive Dentistry, Narayana Dental College and Hospital, Nellore-524003, Andhra Pradesh, India; E-mail: nimskrishna2007@gmail.com

ISSN: 2231-2196 (Print)

Received: 12.06 .2020
ISSN: $0975-5241$ (Online)

Revised: 16.07 .2020
Accepted: 08.08 .2020 
In India each year, 3-6 billion injections are given, of which two-thirds of injections are unsafe. In a national survey of medical injection practices by the All India Institute of Medical Science (AIIMS) in 2002-03 reports that 5.8 injections per person per year, of which $32 \%$ were a potential risk to transmit blood-borne viruses due to use of unsterile needles and/or syringes. ${ }^{4}$ In dental treatment, the use of sharp instruments in the presence of blood and saliva along with diverse bacterial flora in the oral cavity, which all contribute to the insecure nature of the dental workplace for blood-borne infections. ${ }^{2}$ Due to the underreporting of incidents among dental HCWs, which became a significant issue in developing countries, it became difficult to estimate the global prevalence of NSIs. ${ }^{5}$

Occupational exposures are common in the developing world, and it believed that $40-75 \%$ of these injuries not reported. Unreported needle stick and sharp injuries are a serious problem and stop injured HCWs from receiving postexposure prophylaxis (PEP) against HIV, which shows to be $80 \%$ effective in preventing HIV infection in these subjects. ${ }^{6}$

There is no reliable surveillance data regarding NSIs in Nellore, Andhra Pradesh, India. Several factors for the underreporting of NSIs presented in the literature. They include a lack of awareness that NSIs need to report, lack of knowledge of where to report, the belief that there is no point in reporting incidents, and unwillingness to report the incident. ${ }^{7}$

The present study intends to evaluate the cognizance, attitude, practice, and prevalence of NSIs and sharp injuries among dental health care professionals in Nellore.

\section{MATERIALS AND METHODS}

This study was conducted in September 2018 using a crosssectional survey among dental professionals in Nellore. A total of 300 dental health care professionals, of which 276 participated and were informed about the design and purpose of the study by using a Convenience sampling technique. Third-year and final year UG students, dental house surgeons, postgraduate students, and dental practitioners were included in the survey as dental health care professionals. The secrecy of the participants maintained throughout the study.

For this study, structured and pretested data was collected. The pretested and predesigned questionnaire consists of a section of demographic items such as age, gender. Another part collected data about knowledge, prevalence, and occurrence of NSIs, cognizance, and practice of universal precaution guidelines and also cognizance about post-exposure prophylaxis (PEP) and safety devices to prevent NSIs. The questionnaire forms included a range of response options designed to identify the practitioner's cognizance, attitude, the practice of the universal precautions, and about their awareness toward NSIs. These questionnaire forms were given to individual dental health care professionals and collected after completing the form.

\section{STATISTICAL ANALYSIS}

The data were entered into MS-Office, Excel, and analyzed using the statistical package, SPSS version 13. The descriptive statistics of the important variables reported; a comparison of these variables between the dental health care professionals made using Pearson's Chi-square test, and the $P$-value for the same calculated.

\section{RESULTS}

The questionnaires distributed to 276 participants, and the rate of response was $100 \%$. The overall mean age of 32.16 years, of which $8.98 \%$ were males, and $71.01 \%$ were female participants. $25.3 \%$ were 3 rd-year dental students, $14.13 \%$ were 4 th-year dental students, $18.84 \%$ were dental surgeons, $32.24 \%$ were postgraduate dental students, and $9.42 \%$ were dental practitioners. The majority $(96.4 ; \mathrm{p}=0.023)$ of the dental professionals well-thought-out hepatitis B, hepatitis C, and HIV/AIDS to be transmitted by NSIs. About $68.1 \%$ respondents reported that injury caused while using all of the instruments (hand, rotary, surgical, hypodermic needles, suture needles, and lancets) constituted NSIs and SIs $(\mathrm{P}<0.001)$. (Table -1$)$. A greater part of the dental professionals knew the Universal Precaution Guidelines (59.1; P < 0.001 ). Almost $67 \%$ of the dental professionals were aware of the safety devices available in the market to prevent NSIs $(P<0.001)$ and $58 \%$ were aware of the PEP in the management of NSIs $(\mathrm{P}<0.001)$ (Table 2$)$.

About $64.5 \%$ of the dental professionals reported that they would first contact a medical emergency room in case of an accidental NSI, 30.1\% reported that they would contact the Oral Surgery Department, 2.5\% would contact their professional colleagues, $1.4 \%$ would contact the Principal and $1.4 \%$ would not contact anyone in case of NSIs $(\mathrm{P}<0.001)$ (Table 3).

About $20.7 \%$ of the dental professionals had an NSI in the past 12 months, resulting in 0.20 NSIs per dental professional per year $(\mathrm{P}<0.001)$. The self-reported reasons that prevented the dental professionals to report NSIs were: $86 \%$ did not report because the injury was due to sterile needle, $12 \%$ reported that they were not aware of the reporting procedures and $2 \%$ was concerned about the confidentiality. $(\mathrm{P}<0.001)$ (Table 4).

Among the dental professionals who had an NSI in the past 12 months, $81 \%$ had it during recapping of the device, $16 \%$ 
had it after device use, before disposal and $3 \%$ had while device recapping. $(\mathrm{P}<0.001)$ (Table 5).

Most of the dental professionals practice and follow one-handed needle recapping technique or scoop technique (72.1\%; $\mathrm{P}<0.001)$. The needle disposal method followed and practised by most of the dental professionals is the use of needle burner and syringe destroyer $(37.0 \%$; $\mathrm{P}<0.001)$ (Table 6).

\section{DISCUSSION}

In India, dentistry is a five-year course. After completion of BDS (Bachelor of Dental surgeon), many start their private practice while few join PG. In BDS, PG, or private practice, they have to treat HIV patients; in such conditions, they should be competent enough to handle the needle stick injuries or any other injuries encountered. ${ }^{7}$ In a few cases, while treating the negative child, there are chances of needle stick injury either to dentists or children; in such situations, dentists should have thorough knowledge regarding needle stick injuries. This study aimed to evaluate the cognizance, attitude, practice, and prevalence of NSIs among dental professionals.

About $96.4 \%$ of the dental professionals considered hepatitis B, hepatitis C, and HIV to be transmitted by NSIs and results were similar to the studies conducted by pavithran et al., ${ }^{2}$ Saini et al., ${ }^{8}$ Guruprasad et al., ${ }^{9}$ Malik et al., ${ }^{10}$ and Kasat et al., ${ }^{7}$ showing that they have adequate knowledge. These study results were in contrast to a study conducted by Alam et al., ${ }^{11}$ who reported $70 \%$ of nurses and paramedical staff were aware that hepatitis B transmitted by NSIs, but $21 \%$ $30 \%$ were unaware of the fact that NSIs can transmit AIDS and hepatitis C.

In this study, Dental professionals had better knowledge, with $68.1 \%$ of respondents considered the injury caused while using all of the instruments such as hand, rotary, surgical, hypodermic needles, suture needles, and lancets constituted NSIs and SIs. These results were contradicting the study conducted by Saini et al., ${ }^{8}$ who reported that hypodermic needles had the highest risk for NSIs with a $28 \%$ response of the dental students. A study reported that transmission occurred only from hollow- bore needles as compared with other sharp objects ${ }^{11}$.

About $59.1 \%$ of dental professionals knew, and $40.9 \%$ of dental professionals did not know about the Universal Precaution Guidelines. It is contradicting with a low level of knowledge to the studies conducted by Bhardwaj et al. ${ }^{12}$ (96.7\%), Jaber ${ }^{13}(92.1 \%)$, George et al. ${ }^{14}(91 \%)$, Malik et al. ${ }^{10}$ (74\%), and Sharma et al. ${ }^{3}$ (73.6\%). These results were by the studies by pavithran ${ }^{2}(58 \%)$, John $\mathrm{S}$ et al. ${ }^{15}(62.6 \%)$, and Alam et al., ${ }^{11}$ (61\%).
Knowledge of the dental health care professionals regarding safety devices to prevent NSIs was adequate, with $67 \%$ were aware of the safety devices, and $33 \%$ were unaware of the safety devices. $88.46 \%$ of dental practitioners and $80.76 \%$ of dental house surgeons had adequate knowledge regarding safety devices to prevent NSIs. The participants had better knowledge regarding safety devices to prevent NSIs than the studies conducted by pavithran et al ${ }^{2}(48 \%)$, Alam et al. ${ }^{11}$ (50\% of HCWs - nurses and paramedical staff), and Malik et al. ${ }^{10}$ (53\% of the dental professionals). This study is contradicting the studies conducted by Jaber et al. ${ }^{13}$ and Prabhu et al. ${ }^{16}$.

In our study, $58 \%$ were aware of the PEP in the management of NSIs, and $42 \%$ were unaware of PEP in the management of NSIs. The participants in this study had adequate knowledge about PEP similar to the studies by Jaber et al., ${ }^{13}$ (54.34\%) and Salekar et al., ${ }^{17}(55.5 \%)$ and had a poor knowledge in comparison to the studies by pavithran et al. ${ }^{2}(69 \%)$ Kasat et al.,7 (68.8\%). So to achieve optimal awareness of PEP, post-exposure incident services should be introduced to students before they begin their clinic experiences.

In the present study, $20.7 \%$ had an NSI in the past 12 months, resulting in 0.20 NSIs per year. This prevalence rate was in accordance to the studies conducted by pavithran ${ }^{2}(27 \%)$, Jaber et al. ${ }^{13}(23 \%)$, Malik et al. ${ }^{10}(30 \%)$, Prabhu et al. ${ }^{16}$ $(33 \%)$, Rais et al. ${ }^{19}(28 \%)$ and Salekar et al. ${ }^{17}(34.8 \%)$. The prevalence of NSIs was contradicting to the other studies conducted nationally and internationally ${ }^{21}$ by Jan S, et al., ${ }^{15}$ (54.2\%), Sahasrabuddhe AG $^{20}$ (63.3\%), Sultana A. ${ }^{22}$ (70.6\%), and Alam M. ${ }^{11}$ (74\%). A significant decrease in the incidence of NSI can achieve by implementing a tangible program, which must include creating cognizance about the risks of NSI, preparing dynamic guidelines, and practising proposed precautions.

About $64.5 \%$ of the dental health care professionals reported that they would first contact a medical emergency room in case of an accidental NSI which was less than the study conducted by Pavithran et al. ${ }^{2}$ (81\%),30.1\% would contact oral surgery department, $2.5 \%$ contact others and $1.4 \%$ would not contact anyone. Similar results found in previous investigations of dentists reported $60 \%$ by Jan et al. ${ }^{15}$ and in medical students reported $75 \%$. The participants in this study had a low response of attitude towards reporting to the concerned authorities regarding NSIs, which is contradicting the study conducted by Pavithran et al., ${ }^{2}$ in which $81 \%$ responded to contact medical emergency room which had a positive attitude towards reporting to the concerned authorities. These results vary in this study may be due to improper awareness regarding the informing procedure.

In the present study, the reasons reported that prevented dental health care professionals from reporting NSIs were that $86 \%$ of the dental health care professionals not reported be- 
cause the injury was due to sterile needle, $12 \%$ don't know the reporting procedure and $2 \%$ of dental health care professionals concerned about confidentiality. Similar to study by Pavithran et al., $2 \%$ of the dental health care professionals thought he/she might get blamed or get into trouble for having an NSI, and $2 \%$ thought it was not important to report. Jan et al. ${ }^{15}$ stated that $33.1 \%$ of dentists did not report, $27.1 \%$ did not know where to report or did not want to report, 19.3\% stated that the needle was new hence there was no need to report, $9 \%$ did not get time to report, $6 \%$ forgot to report, and $5.5 \%$ thought nothing would happen if they do not report. Thus, our study suggests that reporting of NSIs and SIs must intensify among dental health care professionals through enhanced education programs conducted regularly.

The present study evaluated $81 \%$ of dental health care professionals who had an injury during device use, 16\% during devices recapping, and 3\% after device use before disposal. It was mostly the dental practitioners $(100 \%)$ and postgraduate dental students $(75 \%)$ who had an injury during device use. Previous investigations found that recapping a needle was the essential cause of NSIs among dentists. These may attribute to the workload and fatigue among the participants in the current study. Under the Occupation Safety and Health Administration (OSHA) Guidelines, the recapping of needles strictly prohibited.

In this study, $72.1 \%$ practised and followed one-handed needle recapping technique (scoop technique), 9.1\% practised two-handed needles recapping, and $18.8 \%$ did not recap the used needle. Of which, $61.5 \%$ of $3^{\text {rd }}$-year dental students do not recap a used needle. It shows that they had less knowledge regarding the recapping of the needle. Improved cognizance and training can reduce NSIs significantly. Muralidhar et al., ${ }^{18}$ Rais et al., ${ }^{19}$ and Prabhu et al., ${ }^{16}$ stated most of the HCWs used both hands while recapping the needle, which is a wrong technique (59\% and $42 \%$, respectively).So, a onehanded scoop technique for recapping may promote widely, and there is evidence that it is highly effective. Scoop technique, the cap is placed on the benchtop with the syringe held in one hand and is the needle slid into the cap, lifted and snapped securely, thus minimizing the risk of injury. Each faculty instructor must reinforce this technique during the clinical sessions.

The present study found that $37 \%$ of the dental health care professionals practised disposal of needles through needle burner and syringe destroyer, $30.1 \%$ used puncture-resistant sealed containers, $18.1 \%$ used needle incinerator, and $14.9 \%$ used needle cutter. A study by Pavithranet al. ${ }^{2}$ stated that $55 \%$ would destroy the needle using needle burner and syringe destroyer. A study by Guruprasad et al. ${ }^{9}$ noted that $44 \%$ would destroy the needle using needle destroyer, and another study by Prabhu et al. ${ }^{16}$ found that $30.39 \%$ of the dental nurses dispose of needles in a puncture-proof sealed box.
It is evident, however, that despite continuous education, there are still some dental students with gaps in their knowledge, which puts them at risk. There is a need to invest resources into educating students on the proper use of devices, focusing on the administration of local anaesthetics, recapping, changing the anaesthetic carpels, and cleaning of instruments, as these factors, contributed to a significant proportion of NSIs. Perhaps in addition to education, there is a need to introduce needle stick protection devices to offer protection. There is a need for standardized procedures and interventions to minimize the exposure and avert accidental needle stick injury. We can use new, safer techniques of needle and sharps to reduce the risk of accidental exposure to blood-borne pathogens.

There were certain limitations to the study. Firstly, the response of dental health care professionals may vary from what they know and practice because they wanted to portray themselves as more knowledgeable individuals in their respective professions. These might give a chance for the occurrence of social desirability bias. Secondly, recall bias that includes the loss of memory of the events over the past 12 months may vary from each dental professional, leading to the underestimation of the NSIs.

\section{CONCLUSION}

Following conclusions were drawn from the study:-

- The NSIs remains to be a major concern among dental health care professionals

- Dental practitioners and postgraduates were with adequate knowledge regarding NSIs.

- Third-year, Final year students and Dental house surgeons were with poor knowledge regarding NSIs. So there is a need to educate the dental health care professionals regarding the NSIs and this topic should be added in their dental curriculum as a preventive measure from the NSIs.

\section{ACKNOWLEDGEMENT}

We acknowledge the support of our institution Narayana dental college and hospital for all the help lent in preparing and submitting this manuscript.

\section{Sources of funding - None.}

Conflicts of interest - Nil

\section{REFERENCES}

1. Singhal V, Bora D, Singh S. Hepatitis B in health care workers: Indian scenario. Journal of Laboratory Physicians. 2009; 1(2):41-4 DOI: 10.4103/0974-2727.59697

2. Pavithran VK, Murali R, Krishna M, Shamala A, Yalamalli M, Kumar AV. Knowledge, attitude, and practice of needle stick and 
sharps injuries among dental professionals of Bangalore, India. Journal of International Society of Preventive and Community Dentistry. 2015; 5(5):406-12. DOI: 10.4103/2231-0762.165932

3. Sharma R, Rasania S, Verma A, Singh S. Study of Prevalence and Response to Needle Stick Injuries among Health Care Workers in a Tertiary Care Hospital in Delhi, India. Indian J Community Med. 2010; 35(1):74-7. DOI: 10.4103/0970-0218.62565

4. Correa M, Gisselquist D. HIV from blood exposures in India-An exploratory study. Colombo: Norwegian Church Aid. 2005.P-31

5. Pervaiz M, Gilbert R, Ali N. The prevalence and under-reporting of needlestick injuries among dental healthcare workers in $\mathrm{Pa}$ kistan: a systematic review. International journal of dentistry. 2018; 1-14 DOI: 10.1155/2018/9609038

6. Goel V, Kumar D, Lingaiah R, Singh S. Occurrence of needlestick and injuries among health-care workers of a tertiary care teaching hospital in North India. Journal of laboratory physicians. 2017; 9(1) 20-25 DOI: 10.4103/0974-2727.187917

7. Kasat VO, Saluja H, Ladda R, Sachdeva S, Somasundaram VK, Gupta A. Knowledge, attitude and practices toward post-exposure prophylaxis for human immunodeficiency virus among dental students in India. Annals of medical and health sciences research. 2014; 4(4):543-8. DOI: 10.4103/2141-9248.139308

8. Saini R. Knowledge and awareness of needlestick injury among students of Rural Dental College, Maharashtra, India. Annals of Nigerian Medicine. 2011; 5(1):12-6 DOI: 10.4103/03313131.84221

9. Guruprasad Y, Chauhan DS. Knowledge, attitude and practice regarding the risk of HIV infection through accidental needlestick injuries among dental students of Raichur, India. National Journal of maxillofacial surgery. 2011; 2(2):152-5 DOI: 10.4103/0975-5950.94470.

10. Malik A, Shaukat MS, Qureshi A. Needle-stick injury: A rising bio-hazard. Journal of Ayub Medical College Abbottabad. 2012; 24(3-4):144-6.

11. Alam M. Knowledge, attitude and practices among health care workers on needle-stick injuries. Annals of Saudi Medicine. 2002; 22(5-6):396-9. DOI: 10.5144/0256-4947.2002.396.
12. Bhardwaj A, Sivapathasundaram N, Yusof M, Minghat A, Swe K, Sinha N. The Prevalence of Accidental Needle Stick Injury and their Reporting among Healthcare Workers in Orthopaedic Wards in General Hospital Melaka, Malaysia. Malays Orthop J. 2014; 8(2):6-13. doi: 10.5704/MOJ.1407.009.

13. Jaber MA. A survey of needle sticks and other sharp injuries among dental undergraduate students. Int J Infect Control. 2011; 7(3): 1 doi.org/10.3396/ijic.v7i3.5360

14. George B, Brigi C, Mulamoottil VM, Cherian SU. Awareness of infection control procedures among dental students in a dental school in South Kerala. Health Sci. 2014; 1:1-7.

15. Jan S, Akhund T, Akhtar MJ, Shaikh JM. Needlestick injuries among dental health care providers: a survey done at Hyderabad and Karachi. Pakistan Oral and Dental Journal. 2014; 34(2): 3-6

16. Prabhu A, Rao AP, Reddy V, Sugumaran K, Mohan G, Ahamed S. Needle safety awareness among dental nurses. Workplace health and safety. 2014; 62(6):243-8. DOI: 10.1177/216507991406200604.

17. Salelkar S, Motghare DD, Kulkarni MS, Vaz FS. Study of needle stick injuries among health care workers at a tertiary care hospital. Indian journal of public health. 2010; 54(1):18-9 DOI: 10.4103/0019-557X.70540

18. Muralidhar S, Kumar Singh P, Jain RK, Malhotra M, Bala M. Needlestick injuries among health care workers in a tertiary care hospital of India. Indian Journal of Medical Research. 2010; 131(3):405-9

19. Rais N, Jamil HM. Prevalence of needle stick injuries among health care providers. Int J Endorsing Health Sci Res. 2013; 1(2):73-9.Sahasrabuddhe AG, Suryawanshi SR, Khare R. Determinants of occupational exposure to bloodborne pathogens among resident doctors in a tertiary care hospital in the city of Mumbai. Int J Med Sci Public Health. 2014; 1(3):1014-7.21. DOI: 10.5455/ijmsph.2014.170420145

20. Ebrahimi H, Khosravi A. Needle stick injuries among nurses. Journal of research in health sciences. 2007; 7(2):56-62

21. Sultana A. Needle Stick/Sharp Injuries in Health Care Workers. Journal of Rawalpindi Medical College. 2014; 18(1):133-5.

Table 1: Cognizance regarding NSIs among dental professionals

\begin{tabular}{|c|c|c|c|c|c|c|c|}
\hline \multicolumn{8}{|c|}{ No of respondents (\%) } \\
\hline & 3 year & 4 year & interns & PG & DP & Total & P-value \\
\hline \multicolumn{8}{|l|}{ Diseases transmitted by NSIs are } \\
\hline Hepatitis B & $1(100)$ & $\mathrm{o}(\mathrm{o})$ & $\mathrm{o}(\mathrm{o})$ & $\mathrm{o}(\mathrm{o})$ & $\mathrm{o}(\mathrm{o})$ & $1(0.4)$ & \multirow{4}{*}{$0.023^{*}$} \\
\hline Hepatitis C & $6(100)$ & $o(0)$ & $o(0)$ & $o(0)$ & $\mathrm{o}(\mathrm{o})$ & $6(2.2)$ & \\
\hline HIV/AIDS & $1(33.3)$ & $1(33.3)$ & $1(33 \cdot 3)$ & $o(0)$ & $\mathrm{o}(\mathrm{o})$ & $3(1.1)$ & \\
\hline All the above & $62(23 \cdot 3)$ & $51(19.2)$ & $51(19.2)$ & $89(33.5)$ & $26(9.8)$ & $266(96.4)$ & \\
\hline \multicolumn{8}{|l|}{ Consider needle stick and sharp injuries } \\
\hline Injury while using hand instruments & $1(100)$ & $o(0)$ & $o(0)$ & $o(0)$ & $o(0)$ & $1(0.4)$ & \multirow{5}{*}{$<0.001^{*}$} \\
\hline Injury while using rotary instruments & $o(0)$ & $1(100)$ & $o(0)$ & $\mathrm{o}(\mathrm{o})$ & $o(0)$ & $1(0.4)$ & \\
\hline Injury while using surgical instruments & $4(80)$ & $\mathrm{o}(\mathrm{o})$ & $1(20)$ & $o(0)$ & $o(0)$ & $5(1.8)$ & \\
\hline $\begin{array}{l}\text { Injury while using hypodermic } \\
\text { needles,suture needles, and lancets }\end{array}$ & $17(21)$ & $7(8.6)$ & $29(35.8)$ & $28(34.6)$ & $o(0)$ & $81(29 \cdot 3)$ & \\
\hline All the above & $48(25.5)$ & $31(16.5)$ & $22(11.7)$ & $61(32.4)$ & $26(13.8)$ & 188(68.1) & \\
\hline
\end{tabular}

Interns $=$ Dental house surgeons $\mathrm{PG}=$ Post graduates $\mathrm{DP}=$ Dental practitioners

Chi Square Test: * $\mathrm{P}<0.05$ (significant) 
Table 2: knowledge about NSIs among Dental professionals

\begin{tabular}{|c|c|c|c|c|c|c|c|}
\hline \multicolumn{8}{|c|}{ No of respondents $(\%)$} \\
\hline & 3 year & 4 year & interns & PG & DP & Total & P-value \\
\hline \multicolumn{8}{|c|}{ Knowledge about universal precaution guidelines } \\
\hline Yes & $20(12.3)$ & $13(8.0)$ & $38(23 \cdot 3)$ & $66(40.5)$ & $26(16.0)$ & $163(59.1)$ & \\
\hline No & $50(44.2)$ & $26(23.0)$ & $14(12.4)$ & $23(20.4)$ & o (o) & $113(40.9)$ & $<0.001^{*}$ \\
\hline \multicolumn{8}{|c|}{ Knowledge on safety devices to prevent NSIs } \\
\hline Yes & $33(17.8)$ & $22(11.9)$ & $42(22.7)$ & $65(35.1)$ & $23(12.4)$ & $185(67.0)$ & $<0.001^{*}$ \\
\hline No & $37(40.7)$ & $17(18.7)$ & $10(11.0)$ & $24(26.4)$ & $3(3 \cdot 3)$ & $91(33.0)$ & \\
\hline \multicolumn{8}{|c|}{ Knowledge on post-exposure prophylaxis in the management of NSIs } \\
\hline Yes & $17(10.6)$ & $23(14.4)$ & $37(23.1)$ & $59(36.9)$ & $24(15.0)$ & $160(58.0)$ & $<0.001^{*}$ \\
\hline No & $53(45 \cdot 7)$ & $16(13.8)$ & $15(12.9)$ & $30(25 \cdot 9)$ & $2(1.7)$ & $116(42.0)$ & \\
\hline
\end{tabular}

Interns = Dental house surgeons; $\mathrm{PG}=$ Post graduates; $\mathrm{DP}=$ Dental practitioners

Chi Square Test: * $\mathrm{P}<0.05$ (significant)

Table 3: Attitude of dental professionals after NSIs

\begin{tabular}{|c|c|c|c|c|c|c|c|}
\hline \multicolumn{8}{|c|}{ No of respondents $(\%)$} \\
\hline & 3 year & 4 year & interns & PG & DP & Total & P-value \\
\hline \multicolumn{8}{|c|}{ First contact person after an NSI } \\
\hline Medical emergency room & $26(14.6)$ & $25(14.0)$ & $19(10.7)$ & $82(46.1)$ & $26(14.6)$ & $178(64.5)$ & \multirow{5}{*}{$<0.001^{*}$} \\
\hline Oral surgery department & $35(42.2)$ & $11(13 \cdot 3)$ & $31(37 \cdot 3)$ & $6(7.2)$ & o (o) & $83(30.1)$ & \\
\hline principal & $3(75 \cdot 0)$ & o $(0)$ & $\mathrm{o}(\mathrm{o})$ & $1(25 \cdot 0)$ & o $(0)$ & $4(1.4)$ & \\
\hline $\begin{array}{l}\text { Would not contact any } \\
\text { one }\end{array}$ & $2(50.0)$ & $2(50.0)$ & o (o) & $\mathrm{o}(\mathrm{o})$ & o (o) & $4(1.4)$ & \\
\hline others & $4(57.1)$ & $1(14 \cdot 3)$ & $2(28.6)$ & $\mathrm{o}(\mathrm{o})$ & $\mathrm{o}(\mathrm{o})$ & $7(2.5)$ & \\
\hline
\end{tabular}

Interns = Dental house surgeons; $\mathrm{PG}=$ Post graduates; $\mathrm{DP}=$ Dental practitioners

Chi Square Test: ${ }^{*} \mathrm{P}<0.05$ (significant)

Table 4: prevalence of NSIs among Dental professionals and their attitude towards NSIs

\begin{tabular}{|c|c|c|c|c|c|c|c|}
\hline & & No of resp & dents (\%) & & & & \\
\hline & 3 year & 4 year & Interns & PG & DP & Total & P-value \\
\hline Is there any Needlestick injur & in the past & months & & & & & \\
\hline Yes & $9(15.8)$ & $1(1.8)$ & $7(12.3)$ & $28(49.1)$ & $12(21.1)$ & $57(20.7)$ & <0 * \\
\hline No & $61(27.9)$ & $38(17.4)$ & $45(20.5)$ & $61(27 \cdot 9)$ & $14(6.4)$ & $219(79 \cdot 3)$ & $<0.001$ \\
\hline If yes, reasons for not reportir & $g$ the NSI & & & & & & \\
\hline Due to sterile needle & $2(4.0)$ & $1(2.0)$ & $7(14.0)$ & $27(55.0)$ & $12(25.0)$ & $49(86.0)$ & \\
\hline $\begin{array}{l}\text { Don't know the reporting } \\
\text { procedure }\end{array}$ & $6(86.0)$ & o (o) & o (o) & $1(14.0)$ & o (o) & $7(12.0)$ & \\
\hline $\begin{array}{l}\text { I thought I might get blamed } \\
\text { or get into trouble for having } \\
\text { NSI }\end{array}$ & o (o) & o $(0)$ & o (o) & o (o) & o $(0)$ & o (o) & $<0.001^{*}$ \\
\hline $\begin{array}{l}\text { I thought it was not impor- } \\
\text { tant to report }\end{array}$ & $\mathrm{o}(\mathrm{o})$ & o (o) & $\mathrm{o}(\mathrm{o})$ & o (o) & o (o) & o (o) & \\
\hline I did not have time to report & o (o) & $\mathrm{o}(\mathrm{o})$ & o (o) & o (o) & o (o) & o $(0)$ & \\
\hline I was confidential & $1(100)$ & o (o) & $\mathrm{o}(\mathrm{o})$ & o (o) & o (o) & $1(2.0)$ & \\
\hline
\end{tabular}

Interns = Dental house surgeons; $\mathrm{PG}=$ Post graduates; $\mathrm{DP}=$ Dental practitioners

Chi Square Test: * $\mathrm{P}<0.05$ (significant) 
Table 5: Occurrence of NSIs among Dental professionals

\begin{tabular}{|c|c|c|c|c|c|c|c|}
\hline \multicolumn{8}{|c|}{ No of respondents (\%) } \\
\hline & 3 year & 4 year & interns & PG & DP & Total & P-value \\
\hline \multicolumn{8}{|l|}{ Occurrence of NSI due to } \\
\hline while device using & $7(15.0)$ & $1(2.0)$ & $5(11.0)$ & $21(46.0)$ & $12(26.0)$ & $46(81.0)$ & \multirow{4}{*}{$<0.001^{*}$} \\
\hline $\begin{array}{l}\text { After device use, before dis- } \\
\text { posal }\end{array}$ & o (o) & o (o) & $2(22)$ & $7(78)$ & o (o) & $9(16.0)$ & \\
\hline While device recapping & $2(100)$ & $\mathrm{o}(\mathrm{o})$ & o (o) & $\mathrm{o}(\mathrm{o})$ & o (o) & $2(3.0)$ & \\
\hline while disposal & $\mathrm{o}(\mathrm{o})$ & $\mathrm{o}(\mathrm{o})$ & $\mathrm{o}(\mathrm{o})$ & $\mathrm{o}(\mathrm{o})$ & o (o) & o (o) & \\
\hline
\end{tabular}

Interns = Dental house surgeons; $\mathrm{PG}=$ Post graduates; $\mathrm{DP}=$ Dental practitioners

Chi Square Test: * $\mathrm{P}<0.05$ (significant)

Table 6: Practice of NSIs among dental professionals

\begin{tabular}{|c|c|c|c|c|c|c|c|}
\hline \multicolumn{8}{|c|}{ No of respondents (\%) } \\
\hline & 3 year & 4 year & interns & PG & DP & Total & P-value \\
\hline \multicolumn{8}{|c|}{ How will you recap a needle after usage } \\
\hline $\begin{array}{l}\text { One-handed needle } \\
\text { recapping }\end{array}$ & $27(13.6)$ & $23(11.6)$ & $38(19.1)$ & $85(42.7)$ & $26(13.1)$ & $199(72.1)$ & \multirow{3}{*}{$<0.001^{*}$} \\
\hline $\begin{array}{l}\text { Two-handed needle } \\
\text { recapping }\end{array}$ & $11(44.0)$ & $4(16.0)$ & $6(24.0)$ & $4(16.0)$ & o $(0)$ & $25(9.1)$ & \\
\hline $\begin{array}{l}\text { I did not recap a used } \\
\text { needle }\end{array}$ & $32(61.5)$ & $12(23.1)$ & $8(15 \cdot 4)$ & o (o) & o (o) & $52(18.8)$ & \\
\hline \multicolumn{8}{|c|}{ How will you dispose of a needle after usage } \\
\hline $\begin{array}{l}\text { Puncture resistance } \\
\text { sealed container }\end{array}$ & $32(38.6)$ & $16(19 \cdot 3)$ & $28(33.7)$ & $7(8.4)$ & $\mathrm{o}(\mathrm{o})$ & $83(30.1)$ & \multirow{4}{*}{$<0.001^{*}$} \\
\hline $\begin{array}{l}\text { Needle burner and } \\
\text { syringe destroyer }\end{array}$ & $8(7.8)$ & $15(14 \cdot 7)$ & $10(9.8)$ & $48(47.1)$ & $21(20.6)$ & $102(37 \cdot 0)$ & \\
\hline Needle incinerator & $28(56.0)$ & $7(14.0)$ & $9(18.0)$ & $6(12.0)$ & $\mathrm{o}(\mathrm{o})$ & $50(18.1)$ & \\
\hline Needle cutter & $2(4.9)$ & $1(2.4)$ & $5(12.2)$ & $28(68.3)$ & $5(12.2)$ & $41(14 \cdot 9)$ & \\
\hline
\end{tabular}

Interns = Dental house surgeons; $\mathrm{PG}=$ Post graduates; $\mathrm{DP}=$ Dental practitioners Chi Square Test: ${ }^{*} \mathrm{P}<0.05$ (significant) 